\title{
Категория «информация»: философский и правовой аспект
}

\author{
Короткина А.С. \\ Пермский государственный национальный исследовательский университет, \\ 614990, Россия, г. Пермь, ул. Букирева, 15 \\ E-mail: korotkina-a@yandex.ru
}

\begin{abstract}
Аннотация. Развитие коммуникационных процессов, средств массовой информации, проникновение информационных технологий во все сферы общественной жизни стало причиной повышения интереса к категории «информация», в том числе к сути и содержанию данного явления. Несмотря на повсеместное использование данного термина, в современной науке отсутствует единство подходов к его определению. Целью настоящего исследования является рассмотрение и обобщение научных, философских и правовых подходов к определению категории «информация» для формирования комплексного представления об информации как основе информационного права. Сделан вывод о том, что информация является сложным и многоуровневым понятием, относящимся к категории первичных, неопределяемых метапонятий. Результаты работы позволяют выработать комплексное представление об информации как основе информационного права, а также скорректировать подходы к использованию данной категории в правовом регулировании.
\end{abstract}

Ключевые слова: информационное право, информационное общество, правовой статус.

Для цитирования: Короткина А.С. 2021. Категория «информация»: философский и правовой аспект. NOMOTHETIKA: Философия. Социология. Право, 46 (3): 533-543. DOI: $10.52575 / 2712-746 \mathrm{X}-2021-46-3-533-543$

\section{Category "Information": Philosophical and Legal Aspects}

\author{
Anna S. Korotkina \\ Perm State University \\ 15 Bukireva St, Perm, Russia, 614990 \\ E-mail: korotkina-a@yandex.ru
}

\begin{abstract}
The entry of humanity into a new stage of social development - the information society, the success that accompanies the spread of information technologies, puts the category "information" on a par with the fundamental, basic philosophical categories, referring it to the fundamental concepts of modern science. The concept of "information" in the modern world is used in the terminological apparatus in the sciences. At the same time, the attempt to determine the content of this category, despite its widespread use, encounters insurmountable difficulties, primarily due to the nature of this category. This circumstance is the basis for the formation of various, often contradictory points of view on this phenomenon. In view of the above, the purpose of this study is to review and summarize the scientific, philosophical and legal approaches to this category. The theoretical basis of the study was the work of scientists of the 19th-20th century. The normative and empirical basis of the work was the current legal regulation and law enforcement practice. The methodological basis of the work consists of general scientific theoretical research methods, including analytical, formal-logical, comparative-legal, historical. It is concluded that information is a complex and multilevel concept that belongs to the category of primary, undetectable meta-concepts. The results of the work allow us to develop a comprehensive understanding of information as the basis of information law, as well as to adjust approaches to the use of this category in legal regulation.
\end{abstract}

Keywords: information law, information society, legal status. 
For citation: Korotkina A.S. 2021. Category "Information": Philosophical and Legal Aspects. NOMOTHETIKA: Philosophy. Sociology. Law series, 46 (3): 533-543 (in Russian). DOI: $10.52575 / 2712-746 \mathrm{X}-2021-46-3-533-543$

\section{Введение}

Вступление человечества на новую ступень общественного развития в информационное общество, успех, сопутствующий распространению информационных технологий, ставит категорию «информация» в один ряд с основополагающими, базовыми философскими категориями, относя ее к фундаментальным понятиям современной науки [Бородкин, 1997, с. 4].

Понятие «информация», а также производные от него термины, используются в терминологическом аппарате большого количества наук, в то же время попытка определить содержание данной категории, несмотря на повсеместное использование, наталкивается на непреодолимые сложности, обусловленные прежде всего ее сложным, многосторонним характером. Данное обстоятельство является основой для формирования различных, зачастую противоречивых точек зрения на это явление.

С учетом изложенного, целью настоящего исследования является рассмотрение и обобщение научных, философских и правовых подходов к категории «информация». Теоретической основой исследования выступили работы ученых XIX-XXI веков. Нормативной и эмпирической базой работы стало текущее правовое регулирование и правоприменительная практика. Методологическую основу работы составили общенаучные теоретические методы исследования, в том числе аналитический, формально-логический, сравнительно-правовой, исторический.

\section{Философские подходы к категории «информация»}

История информации, как и работа с ней, насчитывает около 7 тысяч лет - со времен возникновения шумерской письменности. Существовавшие изначально символьные, графические формы информации видоизменялись, приобретая буквенный, словесный, числовой формат. Изобретение книгопечатания в Китае (VIII в.), появление печатного станка в Германии (XV в.) дали возможность осуществлять тиражирование информации, а также создавать новые средства ее сохранения и передачи: на смену ручному способу приходит тиражирование печатных источников информации. Увеличение количества информации становится толчком к созданию первых поисковых систем, первоначально на алфавитной основе. Последующие технологические открытия (телеграф (1774 г.), фотография (1826 г.), телефон (1876 г.), радио (1895 г.), телевидение (около 1923 г.)) привели к расширению форм использования информации. Создание электронной вычислительной машины (30-е гг. XIX в.) обусловило наиболее значительные изменения в способах работы с информацией, а также всплеск интереса к данной категории как к объекту межотраслевых, комплексных исследований. Именно с этого времени берет свое начало история научного осмысления категории «информация».

Условно изучение феномена информации на онтологическом уровне как базовой философской научной категории ряд авторов делит на три периода: докибернетический, кибернетический и посткибернетический [Кузнецов, 2005]. Необходимо отметить, что указанный подход не является универсальным и критикуется рядом авторов за однобокость, связанную с исключительным его освещением в контексте использования информационных технологий [Петров, 2000].

Докибернетический период начался во времена эллинской, постэллинской цивилизации и завершился, по мнению ряда авторов, периодом промышленной революции конца XIX в. [Кузнецов, 2005], а по мнению ряда иных авторов, сороковыми годами XX в. [Пет- 
ров, 2000] и был связан с традиционным (на философском уровне) пониманием предпосылок существования информационного взаимодействия: информация не была самостоятельным объектом исследования, использовалась в качестве определяющей категории для иных явлений, определялась через отражение как всеобщее свойство материи. Зачастую данная категория рассматривалась с языковой, семантической точек зрения как средство сохранения и передачи знаний, в том числе с использованием синонимичных словообразований. Сам термин «информация» практически не использовался в науке, а упоминались метрические оценки научной терминологии [Урсул, 1973]. Если не относить к данному периоду исследования, проведенные основоположниками кибернетики, по нашему мнению, в более поздний, кибернетический период, комплексный анализ категории «информация» в философских работах не проводился.

Фундаментальные открытия XX в. ознаменовали кибернетический период понимания информации, который был отмечен расцветом электроники, кибернетики, формированием подходов, теорий информации. Впервые как объект самостоятельного научного исследования информация была рассмотрена в работах основоположников кибернетики. В частности, автор математической теории связи К. Шенон, заложив основу разработки вероятностно-статистической теории информации, определил «информацию» как «снимаемую, уничтожаемую неопределенность» [Шенон, 1963], ввел количественные (энтропийные) характеристики информации. Вместе с тем, говоря об информации, он использовал только «сигнальный (субстратный) ее аспект, дающий возможность исчислять информацию» [Дмитриев, 2002, с. 20]. Ограниченность вероятностно-статистической теории информации привела к формированию иных подходов, направленных на преодоление ее недостатков, в том числе алгоритмического, динамического, комбинаторного, топологического, исследовавших в основном количественный аспект информации и вместе с тем вскрывших неоднозначность данной категории.

Продолжая рассмотрение информации как самостоятельной категории, основоположник кибернетики и теории искусственного интеллекта Н. Винер поставил ее в один ряд с такими явлениями, как «материя» и «энергия» [Wiener, 1988], придав ей статус элемента научной картины мира, самостоятельной субстанции, что позволяет считать Винера также основоположником субстанциональной теории информации. Изучая информацию с позиции взаимодействия, то есть передачи, переработки и хранения, он определял ее как «...обозначение содержания, полученного из внешнего мира в процессе нашего приспособления к нему и приспособления к нему наших чувств» [Wiener, 1961]. Данная точка зрения нашла поддержку в работах российских ученых (В.А. Гадасин, Р.Ф. Абдеев, Б.Б. Кадомцев и др.).

Теория отражения как свойства материи сыграла значительную роль в формировании философских подходов к категории «информация». В частности, еще один родоначальник кибернетической эпохи А.Д. Урсул говорил, что «Информация - это разнообразие, которое один объект содержит о другом объекте (в процессе их взаимодействия)» [Урсул, 2010, с. 228]. По мнению В.М. Глушкова, «информация выступает атрибутом всей материи и свойством абсолютно всех материальных объектов - как живых, так и неживых» [Глушков, 1964]. В то же время Н.И. Жуков, Д. И. Дубровский, Г.Г. Вдовиченко и другие исследователи понимали информацию как свойство не всей, а только высокоорганизованной материи [Пахомова, 2013].

В противовес атрибутивному подходу формировалась функциональная концепция информации, приверженцы которой (Д.И. Дубровский, А.М. Коршунов, П.В. Копнин, Б.С. Украинцев, В.В. Вержбицкий, И.И. Гришкин, Н.Н. Моисеев, Г.И. Царегородцев и др.) полагали, что информация «есть свойство лишь самоорганизующихся систем, свя- 
занное с их функционированием, и которое обладает тремя параметрами: синтаксическим, семантическим и прагматическим», при этом «семантические и прагматические параметры связаны с процессами управления и возникают только в управляемых или самоорганизующихся системах» [Лысак, 2015, с. 13].

Представители третьего, системного подхода придавали информации самостоятельный статус, не зависимый от субъекта [Stonier, 1990], говоря об информации, как о «физической величине, сравнимой по значению с понятием энергии в физике» ${ }^{1}$.

С 1950-х годов формируются логико-семантические теории информации, крупнейшими представителями которых было обращено внимание на неотделимость информации от ее носителей, к которым они относили знаки, слова, языки (Д. Кемени, Р. Уэллс, Е.К. Войшвилло, Р. Карнап, И. Бар-Хиллел, Ю.А. Шрейдер).

Сосредоточенность существующих подходов к категории «информация» на формально-количественных, субстанциональных аспектах не отвечала потребностям приобретающих существенный вес социологических наук, что обусловило возникновение прагматических концепций информации, а также переход к посткибернетическому периоду ее исследования. Среди прагматических концепций необходимо отметить аксиологический подход к информации как к социальному феномену, учитывающему анализ роли субъективного фактора и его влияния на информацию, а также выработку критериев ценности информации.

Тема взаимосвязи информации, техники и общества, а также влияния информации на социально-экономическую систему поднята в работах, развивающих идеи постиндустриального общества. Информация рассматривалась как средство расширения сознания, способное стать универсальным средством платежа [McLuhan, 1967], как компонент инфосферы - подсистемы социальной коммуникации [Тоффлер, 1992].

Также в теориях постиндустриализма (М. Кастельс, Д. Белл, И. Масуда, В.Л. Иноземцев, Ф. Махлуп, М. Порат, Т. Стоуньер, Р.Ф. Абдеев, Р.М. Нижегородцев и др.) информация определялась как «базовый ресурс не только экономической деятельности, но и нового этапа развития человечества, эффективность использования которого определяет конкурентоспособность хозяйствующих субъектов и национальных экономик в целом» [Терещенко, 2011]. Однако исследователи не рассматривали информацию как самостоятельную онтологическую категорию, оценивая прежде всего ее роль и значение в формировании постиндустриального (информационного) общества и взаимосвязь с субъектами, ее использующими, а также возможности, которые данная информация предоставляет.

Таким образом, онтологические подходы к информации, начав с математических, вероятно-статических, уделяющих особое внимание количественным аспектам информации, постепенно прошли этапы формирования качественных оценок данной категории, рассматривая ее как неотделимость от носителей информации и ее социального фактора. В настоящее время исследование категории «информация» осуществляется представителями как естественных и технических, так и гуманитарных наук, формируются синергетические подходы к ее изучению, объединяющие количественные и качественные аспекты, а также ставящие вопросы о ценности информации. Не теряют своего значения и атрибутивный, логико-семантический, а также прагматический подходы.

Таким образом, в естественных (точных) науках информация определяется исходя из «свойства вариативности относительно устойчивых материальных состояний объектов, передающих и хранящих информацию» [Камалова, 2017] (объективный подход, субстанциональная, функциональная, атрибутивная концепции). Гуманитарные науки определяют

${ }^{1}$ Берталанфи Л. 1969. Общая теория систем: критический обзор // Исследования по общей теории систем: сборник переводов; общ. ред. и вст. ст. В.Н. Садовского и Э.Г. Юдина. М., Прогресс, $518 \mathrm{c.}$ 
информацию во взаимосвязи с субъектом, ее воспринимающим (сведения, сообщения, данные) (субъективный подход, семантическая, прагматическая концепции).

Изложенное позволяет сделать вывод о дуалистичной природе информации: информация объективна в силу объективности данных, но субъективна в связи с субъективностью применяемых методов. Данное обстоятельство позволяет отнести информацию к категории первичных, неопределимых, предельно общих фундаментальных метапонятий, обладающих высокой (универсальной) степенью обобщения, с уровнем онтологического существования, аналогичным материи, движению, энергии, массе.

\section{Правовые подходы к категории «информация»}

В правовую действительность информация как базовая категория информационного права стала понятийно входить в 90-х годах XX века. Проведенный нами анализ правового поля позволяет сделать вывод, что в нормах права, в юридической науке данное явление не оценивается с учетом его глубинной сущности, обсуждаемой в различных науках на протяжении XX века. По сути, понятие информации сводится к смысловому значению (семантический подход к категории «Информация») и раскрывается через совокупность синонимичных категорий. Более того, правовой наукой так и не сформулирован однозначный подход к пониманию сущности данного явления как «объекта права», «объекта правового регулирования», «объекта правоотношения».

Теоретики права, рассматривая информацию в качестве объекта права, объекта правового регулирования и объекта правоотношения, расходятся во мнениях относительно как содержания данной категории, так и возможных пределов правового регулирования.

В первые годы постсоветского периода ученые исходили из логики, закладываемой в данную категорию советским законодателем. Так, по мнению И.Л. Бачило, информация - это «объект материальный, что дает основание относить ее также и к категории вещей. А это означает, что на нее распространяется право вещной собственности» [Бачило, 1992, c. 32]. А.П. Сергеев говорил, «что информация представляет собой результат интеллектуальной деятельности» [Сергеев, 1994, с. 39].

После включения информации в перечень объектов прав Г.А. Лобанов писал, что информация является товаром [Лобанов, 1997, с. 74]. В.А. Дозорцев описывал информацию как «сведения, сообщаемые одним лицом другому, о ней можно говорить и как о процессе сообщения этих сведений» [Дозорцев, 1996, с. 27]. М.М. Рассолов вкладывал в категорию информация «вещи или действия (продукт или услуги), которые а) предназначены их производителем для доставки определенного знания получателю (потребителю); б) способны пополнить знания получателя без проведения каких-то специальных нетипичных для него действий» ${ }^{1}$. В.А. Копыловым было отмечено, что информация является сложной вещью, включающей в себя материальный носитель ${ }^{2}$. Е.Н. Насонова признавала информацию «объектом гражданских прав в случаях, при которых сведения о лицах, предметах, фактах, событиях, явлениях и процессах находят свое отображение на материальных объектах в виде символов, образов, сигналов и технических решений» [Насонова, 2002, с. 8].

Вместе с тем В.С. Толстой указывал, что «будучи общераспространенной, информация служит удовлетворению потребностей каждого субъекта общества (как свет, воздух, вода и т.п.) и при таких обстоятельствах вряд ли может выступать в качестве предмета прав, в том числе гражданских. Однако если она обособлена от других информационных образований, то может стать предметом обладания определенного субъекта, значит,

${ }^{1}$ Рассолов М.М., Элькин В.Д., Рассолов И.М. 1996. Правовая информатика: управление в сфере предпринимательства. Учебное пособие. М., Юристь, С. 198.

${ }^{2}$ Копылов В.А. 1997. Информационное право. Учебное пособие. М., Юристь, 472 с. 
объектом его прав» ${ }^{1}$. А.Н. Латыев отмечал, что информация по своей сути нематериальна [Латыев, 2004, с. 23]. Данные рассуждения продолжает А.Г. Карташан, говоря, что информационный объект не может рассматриваться как товар, объект права собственности, а институт вещных прав не может быть применен к этому явлению, так как «существует объективная невозможность распространения данного института на нематериальные объекты» [Карташян, 2007, с. 15]. А.А. Антопольский считал, что информацией является «результат сознательной деятельности человека, зафиксированный в любой пригодной для восприятия форме» [Антопольский, 2004, с. 6].

Вариативность приведенных подходов позволяет сделать вывод, что вопрос о категории «информация» может быть отнесен в отечественном правоведении к числу дискуссионных. Вместе с тем проанализированные подходы говорят о том, что в правовой доктрине «подход к информации в основном ограничен отраслевым подходом к ее понятийной интерпретации», носящим односторонний, семантический характер [Пучков, 2020, с. 4], что не может не вызывать обоснованную критику. По сути рассмотренные ранее философские подходы к данной категории не нашли своего отражения в нормах права, при этом большинство теоретиков права, не погружаясь глубоко в сущность данной категории, ограничивают свои исследования используемой законодателем терминологией.

Несмотря на это, большинство авторов придерживаются точки зрения, согласно которой используемый понятийный аппарат достаточен для правового регулирования, поскольку «информация как таковая остается на периферии: право всегда регулирует отношения, связанные с тем или иным информационным объектом, а не с информацией как таковой» [Войнискатис, 2004, с. 34]. Однако переосмысление подходов к данной категории будет способствовать эффективному использованию возможностей данного явления, позволяя разграничивать его с иными, смежными категориями. Более того, с учетом современного тренда на повсеместную цифровизацию деятельности, формирование целостного подхода к категории «информация» позволит в полной мере использовать возможности, предоставляемые современными цифровыми технологиями, а также обеспечивать непротиворечивое правовое регулирование обозначенной сферы деятельности.

\section{Информация как объект правового регулирования}

Объектом правового регулирования информация выступала со времен «тайного» делопроизводства в эпоху средневековья. Официальное юридическое оформление статуса информации датируется сороковыми годами прошлого века.

На конференции ООН в Мехико в 1946 г. была озвучена необходимость закрепления свободы международного информационного обмена, что нашло свое отражение в Резолюции 59(I) Генеральной Ассамблеи ООН «Созыв международной конференции по вопросу о свободе информации». Далее, в 1948 г. в статье 19 Всеобщей декларации прав человека, принятой 10 декабря 1948 г., закреплено право на свободный поиск, получение, передачу, производство и распространение информации. В Окинавской хартии глобального информационного общества, принятой 22 июля 2000 г., информационнокоммуникационные технологии поименованы в качестве одного из наиболее важных факторов, влияющих на формирование общества XXI века. В Декларации принципов, сформулированных на Всемирном Саммите по информационному обществу, проходившем в декабре 2003 года, информационно-коммуникационные технологии указаны в качестве основного инструмента для создания общества, ориентированного на интересы людей, открытого для всех, в котором каждый мог бы создавать информацию и знания, иметь к ним доступ, пользоваться и обмениваться ими, с тем чтобы дать отдельным лицам, общинам и народам возможность в полной мере реализовать свой потенциал.

${ }^{1}$ Толстой В.С. 2009. Гражданское информационное право. Учебник. М., С. 24. 
В Российской Федерации право на свободный поиск, получение, передачу, производство и распространение информации любым способом, соответствующим закону, закреплено в части 4 статьи 29 Конституции Российской Федерации. Данный термин нашел свое отражение в Федеральном законе от 20 февраля 1995 г. № 24-Ф3 «Об информации, информатизации и защите информации», согласно статье 2 которого информация представляла собой «сведения о лицах, предметах, фактах, событиях, явлениях и процессах независимо от формы их представления». Позднее данный термин появился в иных нормативных правовых актах. Вместе с тем сам факт повсеместного включения категории «информация» в правовое поле не создавал условий для последовательного правового регулирования, а скорее отражал факт массовой информатизации сфер деятельности.

В статье 128 Гражданского кодекса Российской Федерации первоначально информация была включена в перечень объектов гражданских прав. Однако ответа на вопрос о правовой природе данной категории, ее месте среди иных объектов гражданских прав законодатель не давал. С принятием Федерального закона от 27 июля 2006 г. № 149-Ф3 «Об информации, информационных технологиях и о защите информации» из состава указанных объектов она была исключена, что вызвало многочисленные споры в среде ученых юристов.

Согласно статье 2 указанного Федерального закона информация представляет собой «сведения (сообщения, данные) независимо от формы их представления». Стоит отметить, что законодатель, исходя из имеющегося опыта правового регулирования, усовершенствовал данную дефиницию, сделав ее более точной и емкой и отойдя от присвоения принадлежности информации к различным объектам. Статьей 5 Федерального закона установлено, что в рассмотренном значении информация определяется как объект публичных, гражданских и иных правовых отношений.

Данное определение расставляет акценты на нематериальной природе информации, и, стоит согласиться с А.В. Минбалевым, строится на семантической теории информации [Минбалеев, 2007, с. 97].

Несмотря на краткий и емкий характер, содержание категории «информация» оставляет открытым ряд вопросов. Имея общий характер, термин использует ряд иных дефиниций, его раскрывающих, к определению терминологии и сущности которых применяется множество подходов и которые по сути являются его синонимами. В отраслевых нормативных правовых актах так или иначе раскрывается соответствующая терминология, либо термин «информация» имеет свой понятийный аппарат.

В частности, самостоятельную специфическую терминологию содержат Закон Российской Федерации от 27 декабря 1991 г. № 2124-1 «О средствах массовой информации», Федеральный закон от 03 декабря 2008 г. № 242-Ф3 «О государственной геномной регистрации в Российской Федерации», Федеральный закон от 13 марта 2006 г. № 38-Ф3 «О рекламе», Федеральный закон от 30 декабря 2004 г. № 218-Ф3 «О кредитных историях», Федеральный закон от 25 января 1998 г. № 128-Ф3 «О государственной дактилоскопической регистрации в Российской Федерации», Федеральный закон от 29 декабря 1994 г. № 78-Ф3 «О библиотечном деле», Федеральный закон от 27 июля 2006 г. № 152-Ф3 «О персональных данных», Федеральный закон от 29 декабря 1994 г. № 77-ФЗ «Об обязательном экземпляре документов», Федеральный закон от 22 октября 2004 г. № 125-Ф3 «Об архивном деле в Российской Федерации», Федеральный закон от 22 октября 2004 г. № 125-Ф3 «Об архивном деле в Российской Федерации», Федеральный закон от 27 июля 2010 г. № 224-Ф3 «О противодействии неправомерному использованию инсайдерской информации и манипулированию рынком и о внесении изменений в отдельные законодательные акты Российской Федерации», а также многочисленные подзаконные нормативные правовые акты.

Анализ используемой в указанных нормативных правовых актах терминологии подтверждает, что в легальном понимании информация как объект правового регулиро- 
вания носит межотраслевой характер и зависит от сферы правового регулирования как любое первичное, не определяемое метапонятие. Содержание данной категории раскрывается в отношении материальных состояний объектов, передающих и хранящих информацию, а также субъектов, ее воспринимающих, что отражает дуалистический характер информации.

\section{Заключение}

В связи со становлением информационного общества современная философия обратилась к исследованию информационной проблематики, используя подходы естественных, технических и гуманитарных наук. Указанная проблематика в последнее десятилетие находит свое отражение и в правовых науках. Информационное право, не признаваемое рядом теоретиков права, встраивается в существующую правовую действительность.

Как было отмечено ранее, информация является системообразующей категорией информационного права, предметной областью познавательной деятельности данной науки, а также по сути существенным объектом интереса человека на протяжении всей его истории. Многообразие форм существования информации, точек зрения на сущность данного явления, ее свойств и признаков ставят ее в один ряд с базовыми философскими категориями, а возможности использования превращают в «кровь» современного мира.

Вместе с тем отсутствие концептуально оформленного подхода к информации негативно сказывается на системном осмыслении роли данной категории в информационном обществе. Обозначенные проблемы являются причиной формирования различных точек зрения на цель, предмет, объект, методы науки информации права, что впоследствии негативно отражается на возможностях правового регулирования.

Проведенное исследование позволяет сделать выводы, что информация является сложным и многоуровневым понятием, относящимся к категории первичных, неопределяемых метапонятий. Содержание данной категории раскрывается в отношении материальных состояний объектов, передающих и хранящих информацию, а также субъектов ее воспринимающих, что отражает ее дуалистический характер.

Формирование подходов, концепций, теорий к определению сущности и содержания категории «информация» детерминировано соответствующей исторической эпохой и превалирующими в соответствующий период времени подходами.

На основании вышесказанного можно сделать вывод о необходимости продолжения поиска как универсальных, так и практических подходов к пониманию информации как базовой категории информационного права, что позволит сформировать более стройную систему научного знания и скорректировать подходы к использованию данной категории в правовом регулировании.

\section{Список литературы}

1. Антопольский А.А. 2004. Правовое регулирование информации ограниченного доступа в сфере государственного управления. Автореф. дисс. ... канд. юрид. наук. М., 29 с.

2. Бачило И.Л. 1992. О праве собственности на информацию. Труды Института законодательства и сравнительного правоведения, 52: $134 \mathrm{c.}$

3. Бородкин Л.И. 1997. Историческая информатика: Этапы развития. Новая и новейшая история, 1: 3-22.

4. Войникайнис Е.А., Якушев М.В. 2004. Информация. Собственность. Интернет. Традиция и новеллы в современном праве. М., Волтерс Клувер, 176 с.

5. Глушков В.М. 1964. О кибернетике как науке. Кибернетика, мышление, жизнь. М., Наука, $511 \mathrm{c}$.

6. Дмитриев Е.А. 2002. Философский анализ информации как сущностной стороны социальной реальности: Дис. ... канд. филос. наук. Кемерово, 21 с. 
7. Дозорцев В.А. 1996. Информация как объект исключительного права. Дело и право, 4: $27-38$.

8. Ёмирзоева Е.А. 2018. "Информация" и "знание": анализ соотношения статуса понятий в условиях информационного общества. Вестник Таджикского государственного университета права, бизнеса и политики. Серия гуманитарных наук, 1 (74): 48-57.

10. Камалова Г.Г. 2017. Информация как правовая категория: развитие концептуальных подходов. Ученые записки Крымского федерального университета имени В.И. Вернадского «Юридические науки», 3 (69): 185-192.

11. Карташян А.Г. 2007. Гражданско-правовой режим коммерческой информации: Автореф. дис. ... канд. юрид. наук. М., 26 с.

12. Кузнецов П.У. 2005. Теоретические основания информационного права: Дис. ... докт. юрид. наук. Екатеринбург, 55 с.

13. Кушнир Д.Ю. 2018. Информация: социально- философская концептуализация понятия. Гуманитарий юга России, 4: 141-148.

14. Латыев А.Н. 2004. Вещные права в гражданском праве: понятие и особенности правового режима: Дис. ... канд. юрид. наук. Екатеринбург, 211 с.

15. Лобанов Г.А. 1998. Информация как объект гражданских правоотношений. Бизнесадвокат, 6: 72-84.

16. Лысак И.В. 2015. Информация как общенаучное и философское понятие: основные подходы к определению. Философские проблемы информационных технологий и киберпространства, 2 (10): 9-26.

17. Минбалеев А.В. 2007. Категория «Информация» в законодательстве стран ближнего зарубежья: сравнительный анализ. Вестник ЮУрГУ. Серия «Право», 28 (100): 96-98.

18. Насонова Е.Н. 2002. Информация как объект гражданского права. Автореф. дис. ... канд. юрид. наук. М., 23 с.

19. Пахомова В.А. 2013. Понятие термина «информация» и его историческое развитие. Вестник ЮУрГУ. Серия «Право», 4: 59-63.

20. Петров В.К. 2000. Информация как объект познания и средство социального управления: Социально-философский аспект: Дис. ... канд. филос. наук. Уфа, 18 с.

21. Проскурин А.С. 2016. Понятие правовой информации как основы информационного общества. Вестник Волгоградского государственного университета: 1(30): 51-57.

22. Полякова Т.А. 2016. Базовые принципы правового обеспечения информационной безопасности. Труды института государства и права РАН, 3 (55): 17-40. 135-144.

23. Пучков В.О. 2020. Информация - объект гражданского права? Арбитражные споры, 2:

24. Сергеев А.П. 1994. Авторское право России. СПб., 311 с.

25. Сокольская В.В. 2017. Информационная парадигма современности: эпистемологический аспект. Проблемы современной науки и образования, 7 (89): 117-119.

26. Сухих Н. И. 2016. Три уровня рассмотрения категории «информация». Вестник Вятского государственного гуманитарного университета, 2: 20-24.

27. Терещенко Л.К. 2011. Правовой режим информации: Дис. ... докт. юрид. наук. М., 54 с.

28. Тоффлер Э. 1992. Проблемы власти на пороге XXI века. Свободная мысль, 2: 113-120.

29. Урсул А.Д. 1973. Отражение и информация. М., 231 с.

30. Урсул А.Д. 2010. Природа информации: философский очерк. Челябинск, 231 с.

31. Шеннон К. 1963. Работы по теории информации и кибернетики. М., Изд-во иностранной лит-ры, 829 с.

32. Bertalanfi L. 1969. Obshchaya teoriya sistem: kriticheskii obzor [General System Theory]. General Systems, VII: 1-20.

33. Floridi, L. 2003. Two Approaches to the Philosophy of Informatio. Minds and Ma-chines, 13(4): 459-469.

34. Fetzer, J.H. 2004. Information, Misinformation, and Disinformation. Minds and Ma14(2), 223-229 (2004)

35. McLuhan M. 1967. Understanding media: The extensions of man. London, $464 \mathrm{p}$.

36. Stonier T. 1990. Information and the Internal Structure of the Universe: An Exploration into Information Physics. London: Springer-Verlag, 155 p. 
37. Wiener N. 1961. Cybernetics: Or Control and Communication in the Animal and the Machine. Paris: Hermann \& Cie, Camb. Mass. (MIT Press), 244 p.

38. Wiener N. 1988. The Human Use of Human Beings: Cybernetics and Society. Da Capo Press, $204 \mathrm{p}$.

\section{References}

1. Antopol'skii A.A. 2004. Pravovoe regulirovanie informatsii ogranichennogo dostupa v sfere gosudarstvennogo upravleniya [Legal regulation of restricted access information in the field of public administration]. Abstract. dis. ... cand. leg. sciences. M., 29 p.

2. Bachilo I.L. 1992. O prave sobstvennosti na informatsiyu [About the ownership of information]. Trudy Instituta zakonodatel'stva i sravnitel'nogo pravovedeniya, 52: $134 \mathrm{p}$.

3. Borodkin L.I. 1997. Istoricheskaya informatika: Etapy razvitiya [Historical Computer Science: Stages of development]. Novaya i noveishaya istoriya, 1: 3-22.

4. Voinikainis E.A., Yakushev M.V. 2004. Informatsiya. Sobstvennost'. Internet. Traditsiya i novelly v sovremennom prave [Information. Property. The Internet. Tradition and novellas in modern law]. M., Publ. Volters Kluver, 176 p.

5. Glushkov V.M. 1964. O kibernetike kak nauke. Kibernetika, myshlenie, zhizn' [About cybernetics as a science. Cybernetics, thinking, life]. M., Publ.: Nauka, 511 p.

6. Dmitriev E.A. 2002. Filosofskii analiz informatsii kak sushchnostnoi storony sotsi-al'noi real'nosti [Philosophical analysis of information as an essential aspect of social reality]: Dis. ... cand. filos. sciences. Kemerovo, $21 \mathrm{p}$.

7. Dozortsev V.A. 1996. Informatsiya kak ob"ekt isklyuchitel'nogo prava [Information as an object of exclusive right]. Delo i pravo, 4: 27-38.

8. Emirzoeva E.A. 2018. "Information" and "Knowledge": correlation analysis of the status of concepts in informational society. Vestnik Tadzhikskogo gosudarstvennogo universiteta prava, biznesa i politiki. Seriya gumanitarnykh nauk, 1 (74): 48-57.

9. Kamalova G.G. 2017. Informatsiya kak pravovaya kategoriya: razvitie kontseptual'nykh podkhodov [Information as a legal category: the development of conceptual approaches]. Uchenye zapiski Krymskogo federal'nogo universiteta imeni V.I. Vernadskogo «Yuri-dicheskie nauki», 3 (69): 185-192.

10. Kartashyan A.G. 2007. Grazhdansko-pravovoi rezhim kommercheskoi informatsii [Civillegal regime of commercial information]: Abstract. dis. ... cand. leg. sciences. M., 26 p.

11. Kolin K. K. 2015. Filosofskie tezisy o prirode informatsii [Philosophical theses on the nature of information]. Vestnik Mezhdunarod-noi akademii nauk (Russkaya sektsiya), 1 (17): 52-58.

12. Kuznetsov P.U. 2005. Teoreticheskie osnovaniya informatsionnogo prava [Theoretical foundations of information law]: Abstract. dis. ... doct. leg. sciences. Ekaterinburg, 55 p.

13. Kushnir D.Yu. 2018. Informatsiya: sotsial'no- filosofskaya kontseptualizatsiya ponyatiya [Information: socio-philosophical conceptualization of the concept]. Gumanitarii yuga Rossii, 4: 141-148.

14. Latyev A.N. 2004. Veshchnye prava v grazhdanskom prave: ponyatie i osobennosti pravovogo rezhima [Real rights in civil law: the concept and features of the legal regime]: Dis. ... cand. leg. sciences. Ekaterinburg, $211 \mathrm{p}$.

15. Lobanov G.A. 1998. Informatsiya kak ob"ekt grazhdanskikh pravootnoshenii [Information as an object of civil legal relations]. Biznes-advokat, 6: 72-84.

16. Lysak I.V. 2015. Informatsiya kak obshchenauchnoe i filosofskoe ponyatie: osnovnye podkhody k opredeleniyu [Information as a general scientific and philosophical concept: basic approaches to the definition]. Filosofskie problemy informatsionnykh tekhnologii i kiberprostran-stva, 2 (10): 9-26.

17. Minbaleev A.V. 2007. Kategoriya «Informatsiya» v zakonodatel'stve stran blizhnego zarubezh'ya: sravnitel'nyi analiz [The category of "Information" in the legislation of neighboring countries: a comparative analysis]. Vestnik YuUrGU. Seriya «Pravo», 28 (100): 96-98.

18. Nasonova E.N. 2002. Informatsiya kak ob"ekt grazhdanskogo prava [Information as an object of civil law]. Abstract. dis. ... cand. leg. sciences. M., 23 p.

19. Pakhomova V.A. 2013. Ponyatie termina «informatsiya» i ego istoricheskoe razvitie [The concept of the term "information" and its historical development]. Vestnik YuUrGU. Seriya «Pravo», 4: 59-63.

20. Petrov V.K. 2000. Informatsiya kak ob"ekt poznaniya i sredstvo sotsial'nogo upravle-niya: Sotsial'no-filosofskii aspekt [Information as an object of cognition and a means of social management: Socio-philosophical aspect]: Dis. ... cand. filos. sciences. Ufa, 18 p. 
21. Proskurin A.S. 2016. Ponyatie pravovoi informatsii kak osnovy informatsionnogo obshchestva [The concept of legal information as the basis of the information society]. Vestnik Volgogradskogo gosudarstvennogo universiteta: 1(30): 51-57.

22. Polyakova T. A. 2016. Bazovye printsipy pravovogo obespecheniya informatsionnoi bezopasnosti [Basic principles of legal support of information security]. Trudy instituta gosudarstva i prava RAN, 3 (55): 17-40.

23. Puchkov V.O. 2020. Informatsiya - ob"ekt grazhdanskogo prava? [Information is an object of civil law] Arbitrazhnye spory, 2: 135-144.

24. Sergeev A.P. 1994. Avtorskoe pravo Rossii [Copyright of Russia]. SPb., 311 p.

25. Sokol'skaya V.V. 2017. Informatsionnaya paradigma sovremennosti: epistemologiche-skii aspekt [The information paradigm of modernity: an epistemological aspect]. Problemy sovremennoi nauki i obrazovaniya, 7 (89): 117-119.

26. Sukhikh N. I. 2016. Tri urovnya rassmotreniya kategorii «informatsiya» [Three levels of consideration of the "information"category]. Vestnik Vyatsko-go gosudarstvennogo gumanitarnogo universiteta, 2: 20-24.

27. Tereshchenko L.K. 2011. Pravovoi rezhim informatsii [Legal regime of information]: Dis. ... cand. leg. sciences. M., 54 p.

28. Toffler E. 1992. Problemy vlasti na poroge XXI veka [Problems of power on the threshold of the XXI century]. Svobodnaya mysl', 2: 113-120.

29. Ursul A.D. 1973. Otrazhenie i informatsiya [Reflection and information]. M., 231 p.

30. Ursul A.D. 2010. Priroda informatsii: filosofskii ocherk [The nature of information: a philosophical essay]. Publ.: Chelyabinsk, 231 p.

31. Shennon K. 1963. Raboty po teorii informatsii i kibernetiki [Works on the theory of information and cybernetics]. M., Publ.: Izd-vo inostran-noi lit-ry, 829 p.

32. Bertalanfi L. 1969. Obshchaya teoriya sistem: kriticheskii obzor [General System Theory]. General Systems, VII: $1-20$.

33. Floridi, L. 2003. Two Approaches to the Philosophy of Informatio. Minds and Ma-chines, 13(4): 459-469.

34. Fetzer, J.H. 2004. Information, Misinformation, and Disinformation. Minds and Ma14(2), 223-229 (2004).

35. McLuhan M. 1967. Understanding media: The extensions of man. London, $464 \mathrm{p}$.

36. Stonier T. 1990. Information and the Internal Structure of the Universe: An Exploration in-to Information Physics. London: Springer-Verlag, 155 p.

37. Wiener N. 1961. Cybernetics: Or Control and Communication in the Animal and the Machine. Paris: Hermann \& Cie, Camb. Mass. (MIT Press), 244 p. $204 \mathrm{p}$.

38. Wiener N. 1988. The Human Use of Human Beings: Cybernetics and Society. Da Capo Press,

Конфликт интересов: о потенциальном конфликте интересов не сообщалось.

Conflict of interest: no potential conflict of interest related to this article was reported.

\section{ИНФОРМАЦИЯ ОБ АВТОРЕ}

Короткина Анна Сергеевна, доцент, доктор юридических наук, профессор кафедры уголовного процесса Пермского государственного национального исследовательского университета, г. Пермь, Россия

\section{INFORMATION ABOUT THE AUTHOR}

Anna S., Korotkina Associate Professor, Doctor of Law, Professor of the Criminal Procedure Department of the I. D. Putilin Law Institute of Perm State University, Perm, Russia 